\title{
The Characterization, Stability, and Reactivity of Synthetic Calcium Silicate Surfaces from First Principles
}

\author{
E. Durgun, ${ }^{* \dagger, \dagger}$ H. Manzano, ${ }^{\|}$P. V. Kumar, ${ }^{\S}$ and Jeffrey C. Grossman*,§ \\ ${ }^{\dagger}$ UNAM-National Nanotechnology Research Center, Bilkent University, Ankara 06800, Turkey \\ ${ }^{\ddagger}$ Institute of Materials Science and Nanotechnology, Bilkent University, Ankara 06800, Turkey \\ ${ }^{\S}$ Department of Materials Science and Engineering, Massachusetts Institute of Technology, Cambridge, Massachusetts 02139, United \\ States \\ ${ }$ Molecular Spectroscopy Laboratory, Department of Physical Chemistry, University of the Basque Country UPV/EHU, Apartado \\ 644, 48080 Bilbao, Spain
}

Supporting Information

ABSTRACT: Calcium silicate compounds belong to a complicated class of silicates. Among their many industrial applications, calcium silicates are heavily used as a building material as they constitute the main ingredient in today's cement clinker. We report here an extensive surface analysis of synthetic calcium silicate phases (tricalcium silicate, $\mathrm{C}_{3} \mathrm{~S}$, and dicalcium silicate, $\mathrm{C}_{2} \mathrm{~S}$ ) using first-principles computational methods. We calculate surface energies $(\gamma)$ for all lower-index orientations and determine the most stable surfaces as well as the equilibrium Wulff structures. We analyze the variation of $\gamma$ with surface coordination number and find an interesting and unexpected trend where loss of coordination of ionic $\mathrm{Ca}$ and $\mathrm{O}$ atoms can lower $\gamma$. The stability of surface orientations is examined as a function of oxygen partial pressure. Finally, we compute the energy required to remove $\mathrm{Ca}$ from different surfaces and find that it is inversely proportional to $\gamma$, supporting the energetic preference of extracting atoms from higher energy surfaces. Knowledge of the atomic structure and properties of calcium silicate surfaces is important for understanding and controlling the hydration of such systems.

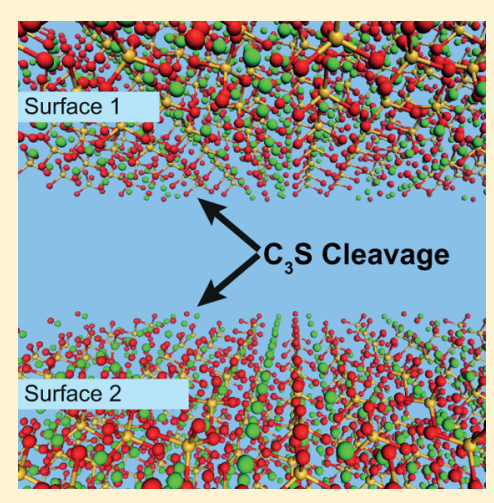

\section{INTRODUCTION}

Calcium silicate represents an interesting and complicated class of silicates, abundant in the earth's crust and important components of many minerals. These compounds have a number of uses in industry, the most important of which are in building materials, such as cement, ${ }^{1,2}$ glass, ${ }^{3}$ paint, and refractories, ${ }^{4}$ although a wide range of other applications include light-emitting diodes, ${ }^{5}$ pharmaceutical products, drug delivery, ${ }^{6,7}$ and as a self-setting material for synthetic bone/ dental recovery and regeneration. ${ }^{8-10}$

Especially in cement production, the compound is usually prepared synthetically in the form of tricalcium silicate $\left(\mathrm{Ca}_{3} \mathrm{SiO}_{5}, \mathrm{C}_{3} \mathrm{~S}\right)$ and dicalcium silicate $\left(\mathrm{Ca}_{2} \mathrm{SiO}_{4}, \mathrm{C}_{2} \mathrm{~S}\right)$ and constitutes the majority of (more than $75 \%$ ) today's cement clinker together with other minerals. ${ }^{11,12}$ The annual production of calcium silicates in the form of clinker exceeding 3 billion tons leaves a huge environmental footprint due to the emission of more than $6 \%$ of anthropogenic $\mathrm{CO}_{2}{ }^{13}$ and thus, new strategies are sought to lower the intense energy requirements involved. ${ }^{14,15} \mathrm{C}_{2} \mathrm{~S}$, which requires substantially lower manufacturing temperatures, reacts much more slowly with water than $\mathrm{C}_{3} \mathrm{~S}$, rendering it less useful. To date, we have little understanding of why certain phases of calcium silicate react differently than others, and even less of a clear picture of how to modify or control the hydration. Since the surface of these materials is the key interface where chemical reactions begin, knowledge of the atomic structure and properties of calcium silicate surfaces is important for understanding and predicting the hydration of such systems. ${ }^{16}$

In this work, we employ first-principles calculations to study and modify the structure and energetics of $\mathrm{C}_{3} \mathrm{~S}$ and $\mathrm{C}_{2} \mathrm{~S}$ surfaces. The surface energy $(\gamma)$ is obtained for all low-index stoichiometric slabs considering multiple geometries that arise from different surface cuts. Using the calculated $\gamma$, the thermodynamically stable crystal structures are obtained via the Wulff construction method. In addition, the surface stability is examined in open air conditions by varying oxygen partial pressure. Finally, the energy required to remove $\mathrm{Ca}$ atoms from the surface (average redox potential), which is linked to dissolution rates, is calculated and compared for the surfaces with highest and lowest $\gamma$.

\section{COMPUTATIONAL DETAILS}

Our calculations are performed within density functional theory (DFT), ${ }^{17,18}$ using the projected augmented wave (PAW) method $^{19}$ implemented in the Vienna $\mathrm{Ab}$ initio Simulation

Received: August 20, 2013

Revised: May 27, 2014

Published: July 3, 2014 

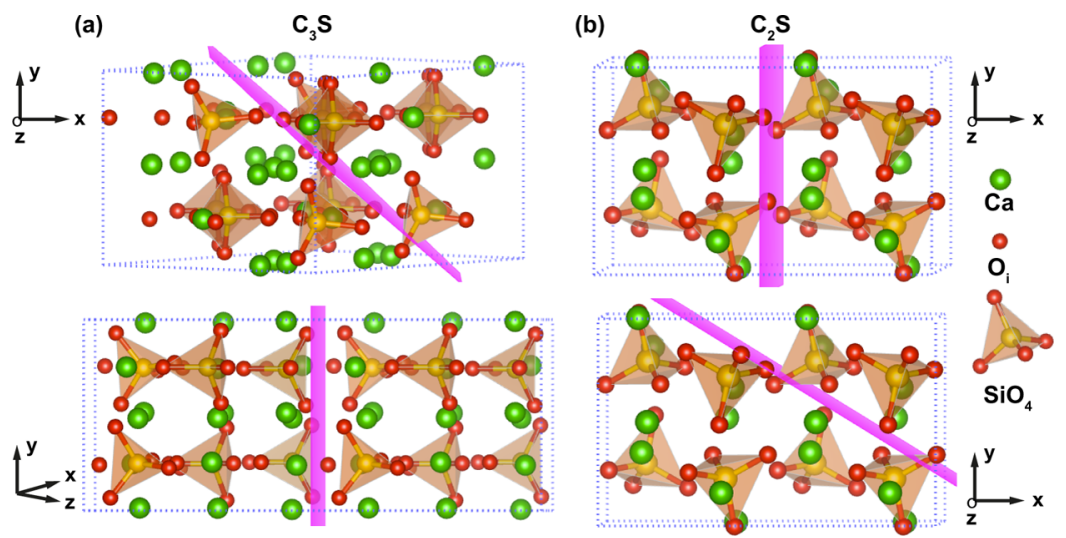

Figure 1. Relaxed crystal structure of $(\mathrm{a}) \mathrm{Ca}_{3} \mathrm{SiO}_{5}$ and $(\mathrm{b}) \mathrm{Ca}_{2} \mathrm{SiO}_{4}$ in two different orientations. The [111] and [100] planes for $\mathrm{C}_{3} \mathrm{~S}$ and [100] and [110] planes for $\mathrm{C}_{2} \mathrm{~S}$ are shown by pink planes. The $\mathrm{Ca}, \mathrm{O}$, and $\mathrm{Si}$ atoms are shown by green, red, and yellow spheres, respectively.

Package (VASP). ${ }^{20-22}$ The exchange-correlation potential is approximated within the generalized gradient approximation (GGA) ${ }^{23}$ The Brillouin zone was sampled with $4 \times 4 \times 1 k$ points ${ }^{24}$ where $x$ and $y$ are the periodic surface plane directions for all considered slab configurations. A plane-wave basis set with a kinetic energy cutoff of $500 \mathrm{eV}$ and a 10 Å vacuum space in the nonperiodic surface normal direction are used (in order to avoid interactions between periodic slab images due to periodic boundary conditions), which have been checked to be sufficient to obtain fully converged results. All structures were relaxed using the Kosugi algorithm ${ }^{25}$ with simultaneous minimization of the total energy and interatomic forces. The convergence on the energy was set to $10^{-5} \mathrm{eV}$, and the maximum residual force allowed on each atom was fixed at 0.01 $\mathrm{eV} / \AA ̊$.

\section{RESULTS AND DISCUSSION}

Surface Structures and Energies. Calcium silicates can exhibit different polymorphs depending on the temperature and/or impurities present. ${ }^{11,26,27}$ In this study, we focus on the $\mathrm{M}-\mathrm{C}_{3} \mathrm{~S}$ and $\beta-\mathrm{C}_{2} \mathrm{~S}$ surfaces as they are the most frequently observed polymorphs in many applications. We started with the relaxed bulk structures, ${ }^{28,29}$ which are shown in Figure 1. M3$\mathrm{C}_{3} \mathrm{~S}$ and $\beta-\mathrm{C}_{2} \mathrm{~S}$ both have monoclinic crystal structures with lattice parameters: $a=9.38 \AA, b=7.20 \AA, c=12.46 \AA(\beta=$ $\left.116.23^{\circ}\right)$ and $a=5.50 \AA, b=6.81 \AA, c=9.36 \AA\left(\beta=94.88^{\circ}\right)$, respectively. The experimental lattice parameters are $a=5.51$ $\AA, b=6.75 \AA, c=9.30 \AA, \beta=94.59^{\circ}$ for $\mathrm{C}_{2} \mathrm{~S}^{30}$ and $a=9.30 \AA, b$ $=7.08 \AA, c=12.22 \AA, \beta=116.08^{\circ}$ for $\mathrm{C}_{3} \mathrm{~S},{ }^{31}$ in good agreement with our computed parameters.

The surfaces are modeled using slabs cut from optimized bulk $\mathrm{C}_{3} \mathrm{~S}$ and $\mathrm{C}_{2} \mathrm{~S}$ structures for all low indices where in-plane crystalline periodicity is retained (Figures 2 and 3 ). The surface terminations for each direction are chosen in order to ensure that the slabs are stoichiometric and are charge neutral. (A charged surface can induce a polarizing electric field throughout the crystal, which generates a diverging electrostatic energy and results in a larger surface energy. ${ }^{32,33}$ ) The charge neutrality constraint also forms plausible physical conditions for anhydrous phases. ${ }^{34}$ The breaking of a $\mathrm{Si}-\mathrm{O}$ bond is energetically costly, so we choose the surface cuts such that the $\mathrm{SiO}_{4}$ tetrahedron is always preserved. ${ }^{35,36}$ There is more than one surface cut for each orientation that satisfies these principles, and we consider multiple surface cuts to determine the slab with the lowest energy configuration (see the (a)

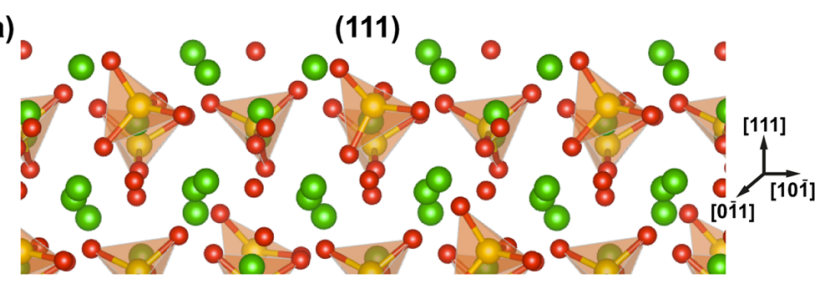

(b)

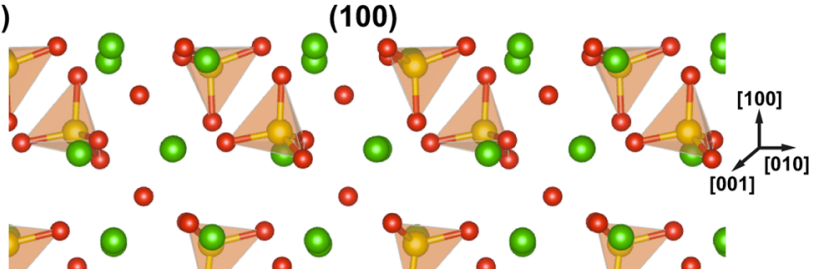

Figure 2. Side view of the $C_{3} S$ (a) (111) and (b) (100) surfaces.

(a)

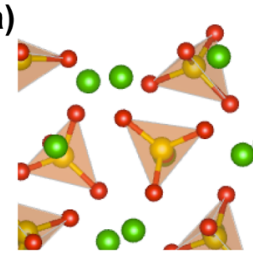

(b)

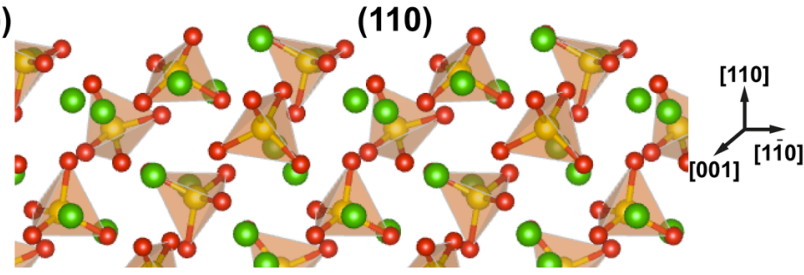

Figure 3. Side view of the $\mathrm{C}_{2} \mathrm{~S}$ (a) (100) and (b) (110) surfaces.

Supporting Information). Because of the complex crystal morphology, the top and the bottom surfaces of the slab may naturally have different atomic arrangements (such as different $\mathrm{SiO}_{4}$ orientation), and we do not impose any symmetry constraints. We allow all atoms in the slab to relax as well as the in-plane lattice parameters of the supercell.

To characterize the surfaces for all orientations, we start by computing the surface energy for a slab of stoichiometric composition, defined as the energy difference between the slab and the equivalent number of bulk formula units, divided by the surface area including both sides of the slab ${ }^{37}$ 
Table 1. Surface Energies $(\gamma)$ and Average Coordination Numbers of $\mathrm{C}_{3} S$ and $\mathrm{C}_{2} \mathrm{~S}$ for Seven Low-Index Orientations ${ }^{a}$

\begin{tabular}{clcccccccc} 
& \multicolumn{1}{c}{ orientation } & bulk & $(100)$ & $(010)$ & $(001)$ & $(110)$ & $(101)$ & $(011)$ & $(111)$ \\
\hline $\mathrm{C}_{3} \mathrm{~S}$ & $\gamma\left(\mathrm{J} / \mathrm{m}^{2}\right)$ & & 1.38 & 1.09 & 1.19 & 0.98 & 1.25 & 1.14 & 0.96 \\
& avg. coord. no. $(\mathrm{Ca})$ & 6.0 & 4.83 & 4.67 & 4.90 & 4.50 & 4.64 & 4.67 & 4.17 \\
& avg. coord. no. $\left(\mathrm{O}_{i}\right)$ & 6.0 & 4.50 & 4.66 & 4.75 & 4.00 & 4.00 & 4.00 & 3.75 \\
$\mathrm{C}_{2} \mathrm{~S}$ & & 0.67 & 0.78 & 0.80 & 0.98 & 0.95 & 0.83 & 0.95 \\
& $\gamma\left(\mathrm{J} / \mathrm{m}^{2}\right)$ & & 5.0 & 5.00 & 5.25 & 5.25 & 5.40 & 5.25 & 5.25
\end{tabular}

${ }^{a_{T}}$ The coordination number of $\mathrm{Si}$ is always 4 as the $\mathrm{SiO}_{4}$ tetrahedron is preserved.
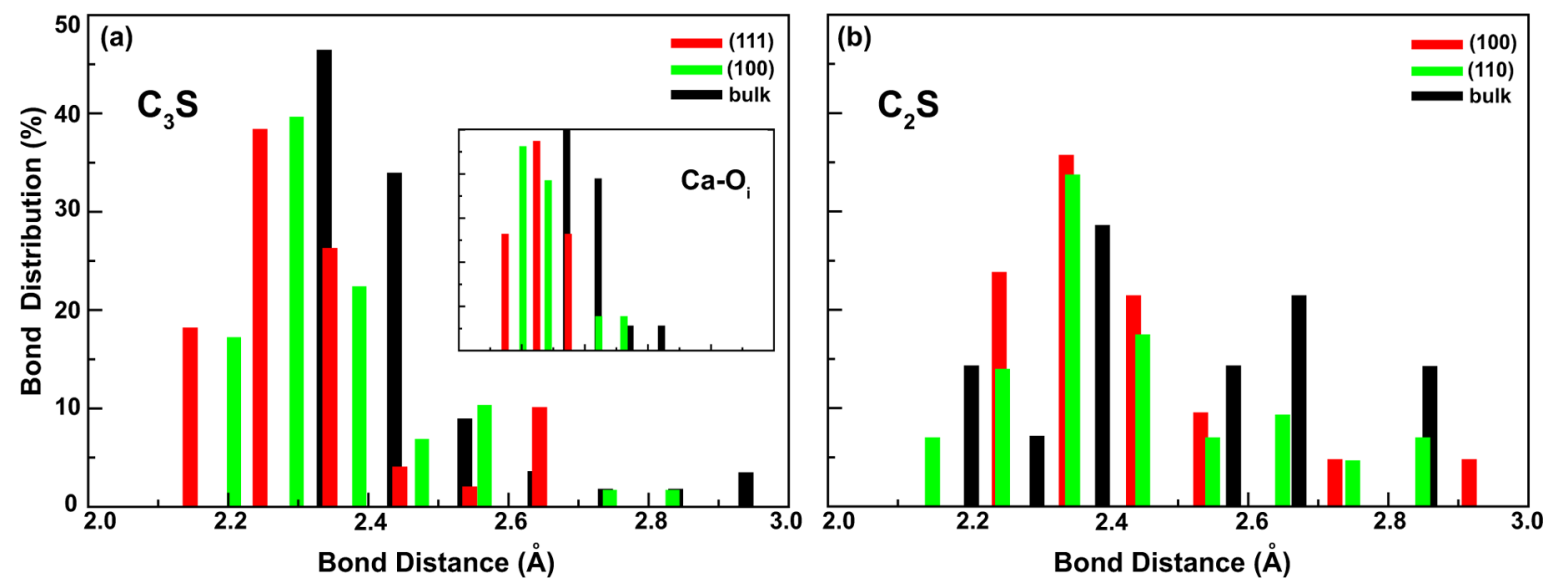

Figure 4. $\mathrm{Ca}-\mathrm{O}$ bond distribution analysis of (a) $\mathrm{C}_{3} \mathrm{~S}(111)$ and (100) surfaces and $\mathrm{C}_{3} \mathrm{~S}$ bulk structure and (b) $\mathrm{C}_{2} \mathrm{~S}(100)$ and (110) surfaces and $\mathrm{C}_{2} \mathrm{~S}$ bulk structure. The inset shows $\mathrm{Ca}-\mathrm{O}_{i}$ bond distribution of $\mathrm{C}_{3} \mathrm{~S}$.

$$
\gamma=\frac{E_{\mathrm{S}}-n E_{\mathrm{B}}}{2 A}
$$

where $E_{\mathrm{B}}$ is the total energy per formula unit of the bulk structure $\left(\mathrm{C}_{3} S\right.$ or $\left.\mathrm{C}_{2} \mathrm{~S}\right), n$ is the number of formula units, $E_{\mathrm{S}}$ is the total energy of the slab containing $n$ formula units, and $A$ is the surface area of the slab. As $\gamma$ varies with slab thickness, the required thickness must be carefully tested to obtain converged values (converged thicknesses range between 25 and $30 \AA$ for the considered slabs). $\gamma$ values for all low-index slabs (only the lowest energy configuration as multiple surface terminations are examined) are reported in Table 1.

On the basis of our calculations, (111) and (100) are the lowest and (100) and (110) are the highest energy surfaces for $\mathrm{C}_{3} \mathrm{~S}$ and $\mathrm{C}_{2} \mathrm{~S}$, respectively (Figures 2 and 3 ). There is a connection between surface energies and their relative stabilities. Higher energy surfaces are generally more reactive, as more intermolecular crystal bonds are broken or disrupted during the surface formation with respect to the crystal form. This is linked to adsorption tendencies of admixtures on these surfaces' orientations.

When the lowest and highest energy surfaces are compared, for $\mathrm{C}_{3} \mathrm{~S}$, the main structural difference lies in the denser $\mathrm{SiO}_{4}$ groups in the (111) and the oxygen-only atomic layers in the (100) orientations. For $\mathrm{C}_{2} \mathrm{~S}$, the structural differences are less significant, but denser $\mathrm{SiO}_{4}$ units in the (110) surface lead to higher $\gamma$ compared to $\mathrm{C}_{3} \mathrm{~S}$. To better understand the structural dependence of $\gamma$, we perform a coordination analysis for all the surfaces studied, summarized in Table 1. Although $\gamma$ generally scales with the degree of undercoordination, a different trend is obtained for $\mathrm{Ca}$ and $\mathrm{O}_{i}$ coordination in our case. Interestingly, the loss of coordination on the surface with respect to bulk actually lowers $\gamma,{ }^{35}$ a result due to the different bonding nature of $\mathrm{Ca}$ (and $\mathrm{O}_{i}$ for $\mathrm{C}_{3} \mathrm{~S}$ ) on the surface compared to bulk. In particular, the 3-4 coordinated $\mathrm{Ca}$ and $\mathrm{O}_{i}$ atoms for $\mathrm{C}_{3} \mathrm{~S}$ and
4-5 coordinated $\mathrm{Ca}$ atoms for $\mathrm{C}_{2} \mathrm{~S}$ are energetically more favorable on the surface. This analysis helps to explain the variation of $\gamma$ for different systems and orientations.

It is also interesting to analyze and compare the bulk and surface $\mathrm{Ca}-\mathrm{O}$ bond distributions (the $\mathrm{Si}-\mathrm{O}$ bond distribution is fixed as $\mathrm{SiO}_{4}$ units remain intact) of $\mathrm{C}_{3} \mathrm{~S}$ and $\mathrm{C}_{2} \mathrm{~S}$. As shown in Figure 4, Ca atoms mainly form bonds with $\mathrm{O}_{i}$ atoms in $\mathrm{C}_{3} \mathrm{~S}$ and have more ionic character when compared to $\mathrm{C}_{2} \mathrm{~S}$. Ca-O bond distances are shorter in $\mathrm{C}_{3} \mathrm{~S}$ surfaces compared to those in $\mathrm{C}_{3} \mathrm{~S}$ bulk, whereas $\mathrm{Ca}-\mathrm{O}$ bond distances in $\mathrm{C}_{2} \mathrm{~S}$ surfaces are about the same as those in $\mathrm{C}_{2} \mathrm{~S}$ bulk. The magnitude of the surface relaxation in $\mathrm{C}_{2} \mathrm{~S}$ is much less than that in $\mathrm{C}_{3} \mathrm{~S}$, indicating a surface resembling bulk bonding behavior, and this gives rise to the comparatively lower $\gamma$ and higher stability of $\mathrm{C}_{2} \mathrm{~S}$ surfaces.

Wulff Construction. A particle of either $\mathrm{C}_{3} \mathrm{~S}$ or $\mathrm{C}_{2} \mathrm{~S}$ will prefer a shape that minimizes its total surface energy, which can lead to complex equilibrium shapes. Nevertheless, once the orientational dependence of $\gamma$ is completely known, the ideal shape of the crystal in the absence of other constraints can be determined by the Wulff construction method. ${ }^{38,39}$ The Wulff shapes for $\mathrm{C}_{3} \mathrm{~S}$ and $\mathrm{C}_{2} \mathrm{~S}$ based on the calculated $\gamma$ (Table 1 ) for low-index orientations are shown in Figure 5. It should be noted that full construction of a Wulff shape requires knowledge of the complete $\gamma$ variation, including high-index orientations. ${ }^{40,41}$ Even if $\gamma$ values for high-index orientations are significantly larger than low-index ones, including them in the plot can mildly modify the obtained Wullf structure and may appear as rounded corners between low-index facets. Nonetheless, our computed structures are able to capture the main characteristics of the $\mathrm{C}_{3} \mathrm{~S}$ and $\mathrm{C}_{2} \mathrm{~S}$ crystal shapes obtained by optical microscope images, ${ }^{42}$ where the sharp edges of $\mathrm{C}_{3} \mathrm{~S}$ and round form of $\mathrm{C}_{2} \mathrm{~S}$ are evident. As (111) forms most of the surface area of $\mathrm{C}_{3} \mathrm{~S}$, we conclude that the observed sharp edges 

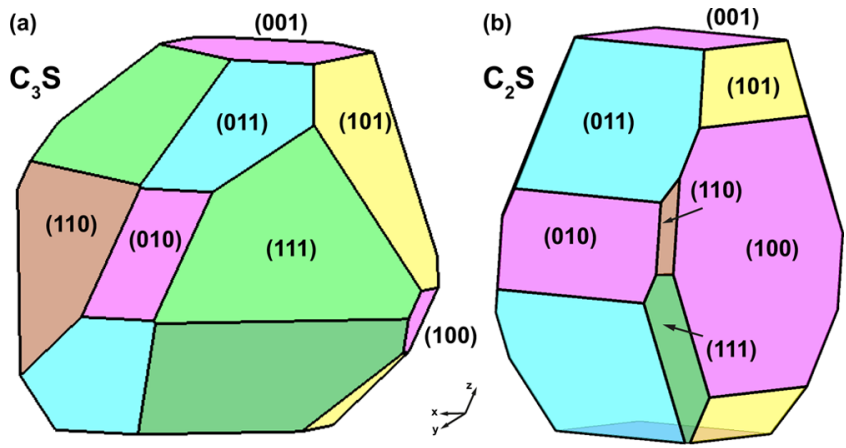

Figure 5. Wulff shapes of (a) $\mathrm{C}_{3} \mathrm{~S}$ and (b) $\mathrm{C}_{2} \mathrm{~S}$ based on the calculated surface energies for all low-index orientations (Table 1).

are mainly (111) surfaces. In $\mathrm{C}_{2} \mathrm{~S}$, even though the (100) surface dominates energetically, the area is more evenly shared, leading to more round or cylindrical shapes.

The surface planes are considered to be thermodynamically stable only if they are part of the Wulff shape. ${ }^{43}$ Accordingly, we can conclude that all low-index surfaces considered here of $\mathrm{C}_{3} \mathrm{~S}$ and $\mathrm{C}_{2} \mathrm{~S}$ are stable. The proportion of the highest energy surfaces in the Wulff shape is low for both cases, indicating the possibility of tuning reactivity if the surface area of these planes can be increased by external factors such as impurities. In industrial applications, $\mathrm{C}_{3} \mathrm{~S}$ and $\mathrm{C}_{2} \mathrm{~S}$ are not pure and already contain impurities, ${ }^{11}$ and it has been shown that inclusion of dopants affects the reactivity profile. ${ }^{44,45}$ It should be noted that there are other factors such as extrinsic defects (stacking faults or dislocations intersecting the surface) that influence the surface reactivity, ${ }^{46,47}$ and it is difficult to separate the effects. In order to tune reactivity with impurities, more controlled production stages are required.

Surface Stability. Thus far, we have presented results for $\gamma$ calculated for stoichiometric surfaces at $0 \mathrm{~K}$ and no pressure. Next, we examine the stability of different surface terminations for the lowest energy $\mathrm{C}_{3} \mathrm{~S}$ (111) and $\mathrm{C}_{2} \mathrm{~S}$ (100) surfaces in an oxygen atmosphere using a simple thermodynamic analysis ${ }^{48}$ combined with the $a b$ initio calculations. Considering the clinker production stages, variation of oxygen pressure corresponds to more realistic conditions for the surfaces studied.

The surface free energy of $\mathrm{C}_{3} \mathrm{~S}$ as a function of oxygen partial pressure $P$ and temperature $T$ can be written as

$$
\begin{aligned}
\gamma(T, P)= & \frac{1}{2 A}\left[G_{\mathrm{C}_{3} \mathrm{~S}}^{\mathrm{slab}}(T, P)-N_{\mathrm{Ca}} \mu_{\mathrm{Ca}}(T, P)-N_{\mathrm{S} \mathrm{j}} \mu_{\mathrm{Si}}(T, P)\right. \\
& \left.-N_{\mathrm{O}} \mu_{\mathrm{O}}(T, P)\right]
\end{aligned}
$$

where $G_{\mathrm{C}_{3} \mathrm{~S}}^{\text {slab }}(T, P)$ is the Gibbs free energy of the $\mathrm{C}_{3} \mathrm{~S}$ slab with two surfaces of area $A, \mu_{\mathrm{Ca}}(T, P), \mu_{\mathrm{Si}}(T, P)$, and $\mu_{\mathrm{O}}(T, P)$ are the chemical potentials, and $N_{\mathrm{C}}, N_{\mathrm{S},}$ and $N_{\mathrm{O}}$ are the number of $\mathrm{Ca}$, $\mathrm{Si}$, and $\mathrm{O}$ atoms, respectively. Chemical equilibrium between the bulk and the surface yields ${ }^{49,50}$

$$
3 \mu_{\mathrm{Ca}}(T, P)+\mu_{\mathrm{Si}}(T, P)+5 \mu_{\mathrm{O}}(T, P)=g_{\mathrm{C}_{3} \mathrm{~S}}^{\text {bulk }}(T, P)
$$

where $g_{\mathrm{C}_{3} \mathrm{~S}}^{\text {bulk }}(T, P)$ is the Gibbs free energy per $\mathrm{C}_{3} \mathrm{~S}$ formula unit. Substituting for $\mu_{\mathrm{Ca}}(T, P)$ in eq 2 leads to

$$
\begin{aligned}
& \gamma(T, P)=\frac{1}{2 A}\left[G_{\mathrm{C}_{3} \mathrm{~S}}^{\text {sla }}(T, P)-\frac{N_{\mathrm{Ca}}}{3} g_{\mathrm{C}_{3} \mathrm{~S}}^{\text {bulk }}(T, P)\right. \\
& \left.-\left(N_{\mathrm{Si}_{\mathrm{i}}}-\frac{N_{\mathrm{Ca}}}{3}\right) \mu_{\mathrm{Si}}(T, P)-\left(N_{\mathrm{O}}-\frac{5}{3} N_{\mathrm{Ca}}\right) \mu_{\mathrm{O}}(T, P)\right]
\end{aligned}
$$

For the case of $\mathrm{C}_{2} \mathrm{~S}$, eq 4 is modified as

$$
\begin{aligned}
& \gamma(T, P)=\frac{1}{2 A}\left[G_{\mathrm{C}_{2} \mathrm{~S}}^{\text {sla }}(T, P)-\frac{N_{\mathrm{Ca}}}{2} g_{\mathrm{C}_{2} \mathrm{~S}}^{\text {bulk }}(T, P)\right. \\
& \left.-\left(N_{\mathrm{Si}}-\frac{N_{\mathrm{Ca}}}{2}\right) \mu_{\mathrm{Si}}(T, P)-\left(N_{\mathrm{O}}-2 N_{\mathrm{Ca}}\right) \mu_{\mathrm{O}}(T, P)\right]
\end{aligned}
$$

The Gibbs free energies in eqs 4 and 5 can be approximated by the total energies obtained from ab initio calculations. ${ }^{49,51-53}$ Accordingly, as $\mu_{\mathrm{Si}}$ is fixed, $\gamma$ variation in an oxygen atmosphere depends only on $\mu_{\mathrm{O}}$. The upper and lower limits of $\mu_{\mathrm{O}}$ are chosen so as to model "oxygen-poor" and "oxygen-rich" environments within a physically reasonable range.

The different surface terminations can be grouped as $\mathrm{Ca}$ - and $\mathrm{SiO}_{4}$-rich for $\mathrm{C}_{3} \mathrm{~S}$ and $\mathrm{C}_{2} \mathrm{~S}$ and $\mathrm{O}_{i}$ - and $\mathrm{Ca}-\mathrm{O}_{i}$-rich for $\mathrm{C}_{3} \mathrm{~S}$ only. For both cases, $\mathrm{SiO}_{4}$-rich surfaces become more stable as oxygen pressure increases, as shown in Figure 6. For all other surface terminations, the stoichiometric case always has the lowest $\gamma$. The results show an increase in $\gamma$ with increasing oxygen pressure when there are more $\mathrm{Ca}$ and $\mathrm{O}_{i}$ atoms on the surfaces, indicating a possible enhancement of surface reactivity as the surface becomes less stable. Interestingly, for Ca-rich surfaces, $\gamma$ of $\mathrm{C}_{2} \mathrm{~S}$ (100) increases significantly, indicating that
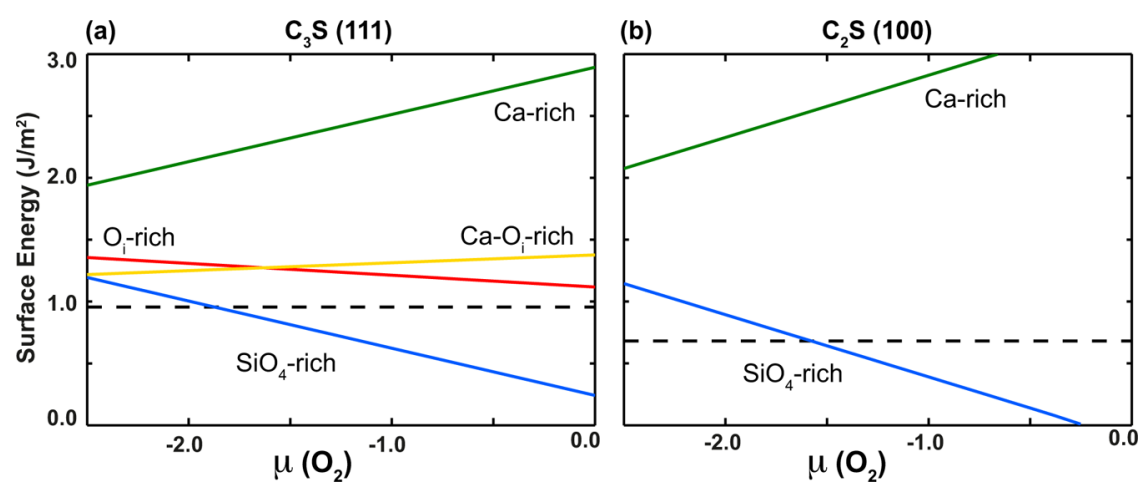

Figure 6. Surface energies of (a) $\mathrm{C}_{3} \mathrm{~S}(111)$ and (b) $\mathrm{C}_{2} \mathrm{~S}(100)$ as a function of oxygen chemical potential. The dashed lines denote stoichiometric surface energies. 
the slow reactivity of $\mathrm{C}_{2} \mathrm{~S}$ surfaces (such as dissolution rates) might be sensitive to the amount of ionic surface formed.

Surface Redox Potential. In addition to classifying the low-index surface orientations via calculations of $\gamma$, it is interesting to examine the required energy variation to remove atoms from surfaces. Following a similar approach to recent work on Li-ion batteries, ${ }^{35}$ the redox potentials $\left(V_{\text {redox }}\right)$ to extract $\mathrm{Ca}$ from a given surface can be calculated. The redox potential where $m \mathrm{Ca}$ atoms are extracted from the $\mathrm{C}_{3} \mathrm{~S}$ and $\mathrm{C}_{2} \mathrm{~S}$ slab can be calculated as

$$
V_{\text {redox }}=-\frac{E\left[\left(\mathrm{C}_{x} \mathrm{~S}\right)_{n}\right]-E\left[(\mathrm{Ca})_{x n-m}\left(\mathrm{SiO}_{4}\right)_{n}\right]}{m}+V_{\mathrm{a}}(\mathrm{Ca})
$$

where $E\left[\left(C_{x} S\right)_{n}\right]\left(x=3\right.$ for $C_{3} S$ and $x=2$ for $\left.C_{2} S\right)$ is the total ground state energy of the slab, ${ }^{54} n$ is the number of slab units, and $V_{\mathrm{a}}(\mathrm{Ca})$ is the reference anode potential for $\mathrm{Ca}$. We calculate $V_{\text {redox }}$ for only the lowest and highest $\gamma$ surfaces of $\mathrm{C}_{3} \mathrm{~S}$ and $C_{2} S$. As the removal of each $\mathrm{Ca}$ on the two surfaces can be energetically different (especially if they are asymmetric), we consider all possibilities for a given orientation one by one and determine $V_{\text {redox }}$ as an average over these values (Table 2). The

Table 2. Average Redox Potentials for the Removal of a Single Ca Atom from the Lowest and Highest $\gamma$ Surfaces of $\mathrm{C}_{3} \mathrm{~S}$ and $\mathrm{C}_{2} \mathrm{~S}$

$\begin{array}{ccccc} & \mathrm{C}_{3} \mathrm{~S}(111) & \mathrm{C}_{3} \mathrm{~S}(100) & \mathrm{C}_{2} \mathrm{~S}(100) & \mathrm{C}_{2} \mathrm{~S}(110) \\ V_{\text {redox }}(\mathrm{V}) & 5.9 & 4.1 & 7.7 & 6.8\end{array}$

results show that $V_{\text {redox }}$ increases with decreasing $\gamma$, which suggests that it is harder to extract $\mathrm{Ca}$ atoms from lower energy surfaces. As discussed in the previous sections, $V_{\text {redox }}$ can be decreased for $\mathrm{C}_{2} \mathrm{~S}$ slabs, if more ionic surfaces can be formed by means of surface engineering.

\section{CONCLUSION}

We report here an ab initio surface analysis of synthetic calcium silicate phases that we believe can serve as a benchmark for further studies. We have calculated the surface energies for all lower-index orientations and have determined the most and least stable surfaces as well as the equilibrium Wulff structures. Our results show an interesting variation of surface energy with coordination number where loss of coordination of $\mathrm{Ca}$ and ionic $\mathrm{O}$ atoms lowers the surface energy unexpectedly. The stability analysis as a function of oxygen partial pressure shows an increase in surface energies for Ca-rich surfaces. The calculated $\mathrm{Ca}$ redox potentials for different surfaces are inversely proportional to the surface energy; thus, it is harder to extract $\mathrm{Ca}$ atoms from lower surface energy orientations.

\section{ASSOCIATED CONTENT}

\section{S Supporting Information}

Figure of multiple surface terminations for $\mathrm{C}_{3} \mathrm{~S}(100)$ is shown. This material is available free of charge via the Internet at http://pubs.acs.org.

\section{AUTHOR INFORMATION}

\section{Corresponding Authors}

*E-mail: durgun@unam.bilkent.edu.tr (E.D.).

*E-mail: jcg@mit.edu (J.C.G.).

\section{Notes}

The authors declare no competing financial interest.

\section{ACKNOWLEDGMENTS}

This work has been supported by the Concrete Sustainability Hub at MIT, with sponsorship provided by the Portland Cement Association (PCA) and the RMC Research and Education Foundation. Calculations were performed, in part, at the National Energy Research Scientific Computing Center, which is supported by the Office of Science of the U.S. Department of Energy under Contract No. DE-AC0205CH11231; in part, by the National Science Foundation through TeraGrid resources provided by TACC under grant number TG-DMR090027; and, in part, at TUBITAK ULAKBIM, High Performance and Grid Computing Center (TR-Grid e-Infrastructure). E.D. acknowledges support from Bilim Akademisi - The Science Academy, Turkey, under the BAGEP program. H.M. acknowledges the Juan de la Cierva postdoctoral contract from the Spanish Ministerio de Industria y Competitividad.

\section{REFERENCES}

(1) Allen, A. J.; Thomas, J. J.; Jennings, H. M. Nat. Mater. 2007, 6, 311-316.

(2) Pellenq, R. J.-M.; Kushima, A.; Shahsavari, R.; Van Vliet, K. J.; Buehler, M. J.; Yip, S.; Ulm, F.-J. Proc. Natl. Acad. Sci. U.S.A. 2009, 106, 16102-16107.

(3) Eckersley, M. C.; Gaskell, P. H.; Barnes, A. C.; Chieux, P. Nature 1988, 335, 525-527.

(4) Rodriguez, J.; Rodriguez, M.; Aza, S. D.; Pena, P. J. Eur. Ceram. Soc. 2001, 21, 343-354.

(5) Kim, J. S.; Park, Y. H.; Kim, S. M.; Choi, J. C.; Park, H. L. Solid State Commun. 2005, 133, 445-448.

(6) Cai, Y.; Pan, H.; Xu, X.; Hu, Q.; Li, L.; Tang, R. Chem. Mater. 2007, 19, 3081-3083.

(7) Xu, Q.; Tanaka, Y.; Czernuszka, J. T. Biomaterials 2007, 28, 2687-2694.

(8) Constantz, B.; Ison, I.; Fulmer, M.; Poser, R.; Smith, S.; VanWagoner, M.; Ross, J.; Goldstein, S.; Jupiter, J.; Rosenthal, D. Science 1995, 267, 1796-1799.

(9) Ding, S.-J.; Shie, M.-Y.; Wang, C.-Y. J. Mater. Chem. 2009, 19, $1183-1190$

(10) Aza, P. D.; Fernandez-Pradas, J.; Serra, P. Biomaterials 2004, 25, 1983-1990.

(11) Taylor, H. F. W. Cement Chemistry, 2nd ed.; Thomas Telford: London, U.K., 1997.

(12) Today's cement is essentially made of a synthetic rock, referred to as clinker, which is a heterogeneous material with at least four distinct phases: alite $(50-70 \%)$, belite $(15-30 \%)$, aluminate (5$10 \%)$, and ferrite $(10-15 \%)$. Alite and belite are solid solutions of tricalcium silicate and dicalcium silicate, respectively, stabilized by a few percent of ionic substitutions.

(13) Damtoft, J.; Lukasik, J.; Herfort, D.; Sorrentino, D.; Gartner, E. Cem. Concr. Res. 2008, 38, 115-127.

(14) Gartner, E. Cem. Concr. Res. 2004, 34, 1489-1498.

(15) Amato, I. Nature 2013, 494, 300-301.

(16) Garrault, S.; Nonat, A. Langmuir 2001, 17, 8131-8138.

(17) Kohn, W.; Sham, L. J. Phys. Rev. 1965, 140, A1133-A1138.

(18) Hohenberg, P. Phys. Rev. 1964, 136, B864-B871.

(19) Blöchl, P. E. Phys. Rev. B 1994, 50, 17953-17979.

(20) Kresse, G.; Hafner, J. Phys. Rev. B 1993, 47, 558-561.

(21) Kresse, G. Comput. Mater. Sci. 1996, 6, 15-50.

(22) Kresse, G. Phys. Rev. B 1996, 54, 11169-11186.

(23) Perdew, J. P.; Burke, K.; Ernzerhof, M. Phys. Rev. Lett. 1996, 77, 3865-3868.

(24) Monkhorst, H.; Pack, J. Phys. Rev. B 1976, 13, 5188.

(25) Diercksen, G. H., Wilson, S., Eds. Methods in Computational Molecular Physics; Springer: Dordrecht, The Netherlands, 1983.

(26) Courtial, M.; De Noirfontaine, M.-N.; Dunstetter, F.; Gasecki, G.; Signes-Frehel, M. Powder Diffr. 2003, 18, 7-15. 
(27) Dunstetter, F.; De Noirfontaine, M.-N.; Courtial, M. Cem. Concr. Res. 2006, 36, 39-53.

(28) Durgun, E.; Manzano, H.; Pellenq, R. J. M.; Grossman, J. C. Chem. Mater. 2012, 24, 1262-1267.

(29) Manzano, H.; Durgun, E.; Abdolhosseine Qomi, M. J.; Ulm, F.J.; Pellenq, R. J. M.; Grossman, J. C. Cryst. Growth Des. 2011, 11, 2964-2972.

(30) Fukuda, K.; Ito, S. J. Am. Ceram. Soc. 1999, 82, 2177-2180.

(31) de Noirfontaine, M.-N.; Dunstetter, F.; Courtial, M.; Gasecki, G.; Signes-Frehel, M. Cem. Concr. Res. 2006, 36, 54-64.

(32) Tasker, P. W. J. Phys. C: Solid State Phys. 1979, 12, 4977.

(33) Noguera, C. J. Phys.: Condens. Matter 2000, 12, R367.

(34) Vandiver, J.; Dean, D.; Patel, N.; Bonfield, W.; Ortiz, C. Biomaterials 2005, 26, 271-283.

(35) Wang, L.; Zhou, F.; Meng, Y.; Ceder, G. Phys. Rev. B 2007, 76, 165435.

(36) Astala, R.; Stott, M. Phys. Rev. B 2008, 78, 75427.

(37) The definition of the surface energy assumes that both surfaces of the slab are symmetric. It should be noted that it is not always the case in our systems, and thus, top and bottom surfaces may have different surface energies. As it is not possible to calculate the surface energies separately, the average value for a slab is reported instead. Therefore, reported values are indeed cleavage energies when top and bottom surfaces are complementary, yet we will maintain the term "surface energy" for simplicity.

(38) Wulff, G. Z. Kristallogr. 1901, 34, 449-530.

(39) Griffith, A. A. Philos. Trans. R. Soc. London, Ser. A 1921, 221, 163-198.

(40) Rottman, C.; Wortis, M. Phys. Rep. 1984, 103, 59-79.

(41) Rottman, C.; Wortis, M. Phys. Rev. B 1981, 24, 6274-6277.

(42) WHD Microanalysis Consultants Ltd, Suffolk, United Kingdom, 2009. http://www.whd.co.uk.

(43) Markov, I. V.; Markov, I. V. Crystal Growth for Beginners: Fundamentals of Nucleation, Crystal Growth and Epitaxy; World Scientific: Singapore, 2003.

(44) Stephan, D.; Wistuba, S. J. Eur. Ceram. Soc. 2006, 26, 141-148.

(45) Kim, Y.-M.; Hong, S.-H. J. Am. Ceram. Soc. 2004, 87, 900-905.

(46) Lasaga, A. C.; Luttge, A. Science 2001, 291, 2400-2404.

(47) Lasaga, A. C.; Lüttge, A. Eur. J. Mineral. 2003, 15, 603-615.

(48) Zangwill, A. Physics of Surfaces; Cambridge University Press: New York, 1988.

(49) Reuter, K.; Scheffler, M. Phys. Rev. B 2001, 65, 035406.

(50) This condition is necessary but can be underconstrained as it treats three components collectively. In addition, a particular stoichiometry on the system is assumed; one cannot be sure that all possible stoichiometric changes have been accounted for when the oxygen chemical potential is varied to simulate different oxygen partial pressures.

(51) The small contributions from the zero-point vibrations, vibrational entropy, and enthalpy changes are neglected.

(52) Xu, X.-L.; Chen, Z.-H.; Li, Y.; Chen, W.-K.; Li, J.-Q. Surf. Sci. 2009, 603, 653-658.

(53) Li, Y.; Yao, K.; Liu, Z. Surf. Sci. 2007, 601, 876-882.

(54) Aydinol, M.; Kohan, A.; Ceder, G. J. Power Sources 1997, 68, 664-668. 